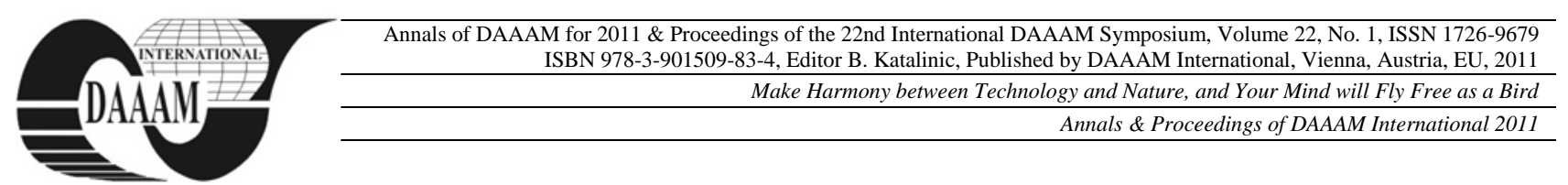

\title{
THE CONCLUSION OF ELECTRONIC CONTRACT
}

\author{
COTOI, E[milia]
}

\begin{abstract}
The electronic trade is the most modern form of commerce used today. For it to come into existence its conclusion needs to be made in electronic form. Because of the technology means used to conclude it, of the distribution and of the place where it is concluded, practice imposed a set of private rules for the conclusion of the electronic contracts, derogatory of Common law. These rules regard both the stage that precedes the conclusion of the contract, and the conclusion itself. The present study will highlight these particular aspects Key words: electronic contract, electronic trade, contract stages, rules for concluding electronic contract, advertising
\end{abstract}

\section{INTRODUCTION}

Technology development has resulted in an unprecedented expansion of electronic trade. The advantages of this system are numerous, but due to the large geographical area that it covers, to the existing legislative differences, there is a need for consistent legislative measures that would ensure users' as well as traders' protection.

These rules regard both the stage that precedes the conclusion of the contract, and the conclusion itself

\section{THE STAGE THAT PRECEDES ELECTRONIC CONTRACT CONCLUSION}

Dynamics and lack of formality in the conclusion of electronic contracts should not automatically lead us to the exclusion of legal protective measures for both the bidder and accepter. This, before concluding electronic contracts, one must follow several steps. Regardless of their duration, we can distinguish two logically successive moments, that is: announcement by each party of its interest and/or acceptance and negotiation of prospective contract clauses. Based on these moments, we shall analyze commercial advertising and contract negotiation.

\section{ADVERTISING AND UNFAIR COMMERCIAL ADVERTISING TECHNIQUES}

Commercial advertising meets a real need, that is, the dealer must draw the consumers' attention on services and products they offer.

The initiative to conclude a contract will belong to the person that wants to fulfill certain needs (to sell, to buy, to rent, etc.), and for this purpose he/she will send a message that in modern commerce is usually done through advertising.

Advertising is ubiquitous in the electronic space, in different forms: as a message sent by electronic mail or mini band message pages linked to pages of a website. Electronic advertising is the big winner of the use of remote electronic communication techniques, dramatically lowering the cost by their using (www.sciencedirect.com).

Simplicity of forms used and the diversity of approaches make it difficult for us to distinguish and detect the real intention of the party that launched the respective advertising message, or its actual offer to conclude a contract.

Doctrines outlined three essential criteria for identifying the message of advertisements: public communication, promotional purpose, and financial counterpart.

However, we must accept that a message can belong simultaneously to both criteria. A message which contains sufficiently detailed information about a trader and its products and services, may represent concomitantly an advertisement and an offer to conclude a contract.

Internet users, as consumers, can come across advertising messages in two different moments: when searching for information in the network, or when using electronic mail. The electronic messages, whether electronic letters or websites, will not be opened and read by the internet user unless he/she is searching for products or services to acquire. The trader's task is to find ways to convince the consumer to read its posts and in this way to receive the information. Many marketing techniques have been created to serve this purpose. But these techniques are not always used in good faith. The most common situation of diverting these means from the purpose for which they were created in the Internet space is by spamming and mousetrapping.

The electronic letter, i.e. the e-mail, is an efficient vehicle of commercial information. Internet users' problems appear when the mail box is filled with unsolicited commercial messages, collectively named spam (http://ec.europa/information_society/policy/current/consumer_rights/securin_telecoms).

Even if European legislation establishes a distinction between spam and unsolicited commercial communication, we will not take into account this distinction, because the unsolicited commercial message disturbs electronic mail users as much as spam does; consequently, we use the term spam to refer to an electronic letter containing an unsolicited commercial message.

The main characteristics of this type of publicity letter are the following: it is a commercial message, it is sent at the trade's initiative (unsolicited by the recipient); it contains the description of a product or service, and on the respective web page there are links to the virtual shop where you can find other products or services, all offered for sale; it is sent to many recipients and it is used before and for the purpose of concluding a deal, a contract.

In most cases the sender is not the same person indicated as contact person, which indicates that the identity of the bidder is being hidden, which in turn could lead to the conclusion that very often we deal with a message meant to deceive rather than with a serious commercial offer (A.. Bleoanca 2010).

\section{REGULATING CONVEYANCE COMMERCIAL MESSAGES BY EMAIL}

Two systems governing the transmission of commercial electronic mail messages through electronic mail have emerged. 
The premise is the observation that sending commercial e-mails cannot be prohibited, because virtual advertising is vital for any kind of trade, thus, the single possible intervention is the regulation of their use.

The opt-in system, according to which consumers who want to receive advertising messages are written in a register, thus accepting to enter the database containing the names and addresses of those who want it, represents an alternative. Merchants are allowed to send messages only to registered people, where the rule is that sending messages is banned, and permission to send messages represents the exception, but only to recipients who have previously accepted this advertising method (F. Mas, 2005).

For the opt-out system, which is symmetrically opposite to the first system, the rule is that sending messages is allowed, but consumers can sign up in an avoidance register and merchants have to check these records and not send advertising messages to those included in the register.

Each system has its own benefits: the first provides greater protection to the sender, whereas the second supports the trader. In the European Union, Directive 2000/31/EC on certain legal aspects of information society services, especially electronic trade, left this choice to the decision of each member state; consequently, some countries have adopted the opt-in system, while the rest decided on the second system. This differentiation between systems created disadvantages for consumers, therefore the European Union tried to obtain the traders', consumers' and legislators' agreement to collect and manage personal information through Directive 2002/58/EC, which refers to the processing of personal data and protection of private life in electronic communication.

\section{THE CONTRACT SIGNING STEP}

The conclusion stage of the contract is synonymous with the agreement will achievement. The doctrine offers the following types, in increasing order of the degree of dematerialization and automation of acceptance: acceptance by e-mail, acceptance by clicking the mouse and acceptance by the action of automated interface the achievement agreement will.

From the juridical point of view it is important to determine at least three aspects regarding the signing of the contract, including: time of concluding the contract, place of concluding the contract and the applicable law regarding the contract.

There are several international legal documents that provide a regulatory model to the time of contract conclusion, among these, the European model agreement for the exchange of computerized documents TEDIS (Trade Electronic Data Interchange Systems). According to this document, the time and the place contract formation by exchange of data is the electronic data message including acceptance of the offer received by the bidder's computer system.

The same solution is also embraced by the model contract regarding the data exchange information of the American Bar Association.

Both systems, the European and the American one use the reception system for determining the moment of reaching the contract.The place of contract conclusion is related to the time of conclusion, where the two wills are meeting.

For such contracts we consider that it is applied the rule regarding the contracts concluded between absent parties. The place where the two wills are meeting represents the place of the tenderer. This solution is based on two arguments. The first is a logical argument based on identity of the situation, based on the principle ubi eadem est ratio, ibi eadem solution esse debet. Therefore, the constant is represented by the physical distance between the sides and the place where the sides are placed. The second reason is technical, represented by the obvious fact that any communication requires a time for the receiver to become acquainted with the message of the originator.

Regarding the applicable law of the electronic contract, we consider it absolutely necessary to show that besides the national electronic contract which is getting applied of the state's national legal system, very often it may take the form of a contract with an international element, because of its crossborder e-commerce character. In this category of contracts we have signed contracts with the element located within the European Union also the report element in a third country, not a member of the European Union.

The Directive nr.2000/31/CE shows that information society services must comply with the laws of the Member State where the service provider is established to ensure effective protection of public interest objectives. For the legal status of a part located in Romania and the other part located in a third country, the applicable law is determined according to the ordinary law.

\section{CONCLUSION}

The new regulation has resulted in the creation of a common European Union opt-in system for the electronic commercial unsolicited mail, for text messages and other electronic messages received by any other fixed or mobile terminal. The European citizens have the right to decide whether their telephone number or email address and postal address is listed or not in public directories, whether electronic tracking devices that are not visible to service users and collect information about them are used only after prior notice on their purpose.

This concern and European legislative initiatives are welcome as they come to protect users from abusive use and conveyance of personal data. Undoubtedly, it is quite difficult for merchants to create and follow a sign up register, and in practice the possibility for a person to enroll in such a register is reduced.

Another major drawback of this initiative is the fact that it is limited to the EU space. As we have reiterated in another paper, because of the simplicity of e-commerce, its worldwide expansion was extremely easily to achieve (E. Cotoi, 2010).

To ensure real protection of all users, as well as real support for traders, these legislative measures must be adopted at international organizations level, in a simple form, that is easy to follow and comprehend.

\section{REFERENCES}

Bleoanca A., (2010), Earlier stage in the electronic contract conclusion, Commercial Law Magazine, number 9, Published at Lumina Lex, Bucharest, pp.46-57, ISSN 12208515

Cotoi E. (2010), Electronic commerce Within the Context of Glogalization, Annals of DAAAM for 2010 \& Procedings of the 21 st International DAAAM Symposium, Vol. 21, ISSN 1726-9679 ISBN 978-3-901509-73-5, Viena Austria, pp.0727-0728

Mas F., (2005), La conclusion de contracts du commerce electronique, Published at Generale de Droit et de Jurisprudence (LGDJ), Paris, ISBN 978-90-04-14554-2) Volume 313, pp. 84

*** Jian $\mathrm{Hu}$, An empirical study of audience impression of $\mathrm{B} 2 \mathrm{C}$ web pages in Japan, China the $U K$, in Electronic Commerce Research and Application, no. 3/2004, pp.176189, Available from http:www.sciencedirect.com; Accessed: 20.06.20110

***http://ec.europa/information_society/policy/current/consum er_rights/securin_telecoms,Accessed: 25.06.2011 